\title{
Spawning Characteristics and Artificial Hatching of Female Mottled Skate, Beringraja pulchra in the West Coast of Korea
}

\author{
Hee-Woong Kang, Yeong-Rok Jo, Duk-Yong Kang, Gyeong-Suk Jeong and ${ }^{\dagger}$ Hyun-Su Jo \\ West Sea Fisheries Research Institute, Incheon 400-420, Republic of Korea
}

\begin{abstract}
The gonadsomatic index (GSI) of mottled skate was the highest in April, GSI and HSI showed a reverse phase for its reproductive cycle. The fish had one pair of egg capsules, having 1 to 7 fertilized eggs, and spawned all the year round. When surveying the reproductive characteristics of females over $63 \mathrm{~cm}$ in disc width, we found the spawning peak was between April to June, and the appearance ratio of egg capsules was the highest in May (32.1\%). The eggs were hatched at $8^{\circ} \mathrm{C}, 13^{\circ} \mathrm{C}, 18^{\circ} \mathrm{C}$, water temperature $\left(12.8\right.$ to $\left.24.2^{\circ} \mathrm{C}\right)$, and the best hatching temperature was $18^{\circ} \mathrm{C}$. The number of fish hatched was 4 to 5 fish/egg capsules, and the hatching rate was $100 \%$. The sex ratios of hatching larvae were $45.5 \%$ female and $54.5 \%$ male. Therefore this study will provide fundamental data and information for artificial reproduction of the mottled skate.
\end{abstract}

Key words : Beringraja pulchra, Closed season, Egg capsule, Hatching, Spawning

\section{INTRODUCTION}

The mottled skate (Beringraja pulchra) is a species of big skate, family Rajidae, in the Rajiformes order. It is found in the Sea of Okhotsk, the Yellow Seas along South Korea, and to as far as the East China Sea (Jeong, 1999; Kim et al., 2005; Ishihara et al., 2012). Skate fish, including mottled skates, are a popular catched, highly consumed, and commercially significant fish along west coast of South Korea. To differentiate the skate fish consumed in South Korea, mottled skate (B. pulchra) is categorised in Heuksan-do Hong-eo, and the red skate (Dasyatis akajei) is categorised as Hong-eo. Female mottled skates need to reach a minimum disc width of $63 \mathrm{~cm}$ to reproduce. Also, they have low annual production (comparing to other species) since they require a longer period for reproduction; hatching requires more than five months (Jo et al., 2010). The mottled skate is one of the most expensive fish on the market at a hundred thousand Korean won per fish. Currently to avoid over-exploitation, there is regulatory control for a seasonal catch (From 1 June until 15 July) and a limit on fish sizes (maximum disc width of $42 \mathrm{~cm}$ ) is practiced to help skate fishery, which was slowly recovered.

There have been basic research on skate species regarding taxonomic studies and classification of common names (Jeong, 1999, 2000), characteristics of $R$. koreana egg capsules (Jeong \& Kim, 2009), it's spawning periods (Kim et al., 2005), and comparative analysis on egg capsule shape (Ishihara et al., 2012). However, there was comparatively less research on the mottled skate (B. pulchra) regarding food habits (Hong et al., 2000), reproduction and spawning (Yeon et al., 1997), fishing characteristics by offshore long line fishery (Jo et al., 2011), characteristics of multi-embryo egg capsules and larvae shape (Jo et al.,

\footnotetext{
Manuscript received 28 August 2013, Received in revised form 2 September 2013, Accepted 10 September 2013

${ }^{\dagger}$ Corresponding Author : Hyun-Su Jo, West Sea Fisheries Research Institute, Incheon 400-420, Republic of Korea. Tel. : +82-32-745-0610, Fax : +82-32-745-0569, E-mail : hyunsujo@korea.kr

This is an Open Access article distributed under the terms of the Creative Commons Attribution Non-Commercial License(http://creativecommons.org/ licenses/by-nc/3.0) which permits unrestricted non-commercial use, distribution, and reproduction in any medium, provided the original work is properly cited.
} 
2010), development on microsatellite markers (Kang et al., 2012), sensory characteristics of domestic mottled skate as affected by area caught, sex and fish weight (Jo et al., 2012), comparison of the nutritional properties (Jo et al., 2013) were exceptions. As the mottled skate is oviparous like hens, with females producing egg capsules almost year-round, it is hard to be produced in mass quantity like other fish species. Reproduction-related research of the mottled skate were conducted thus far since it regularly places multiple embryos into a large egg capsule and produces only a pair of egg capsules at a time every two weeks. Thus, the number of fertilized eggs is limited and it takes more than five months to develop fully formed offspring (Jo et al., 2010). In addition, unlike other fish that hatch in a large rearing tank normally within a month, the mottled skate needs a smaller tank to control environmental conditions and manage it until hatching.

This study aims to examine the spawning ecology of the mottled skate, caught along west coast of the South Korea, by analysing the formation of egg capsule in ovary and the number of fertilized eggs. Also, we investigated the peak spawning season to be able to control seasonal catch limits. We analysed the hatching rate at various water temperatures, hatching time, and the sexual ratio of hatching larvae using our artificial hatching device to obtain basic data for artificial propagation of the mottled skate.

\section{MATERIALS AND METHODS}

\section{Spawning characteristics of mottled skates}

Forty female mottled skates, B. pulchra (average disc width of $72.4 \pm 4.5 \mathrm{~cm}$ average weight $7,460.3 \pm 1,480.9 \mathrm{~g}$ ) collected from offshore long line fishing and bottom trawlers in Heuksan-do and Daecheong-do, South Korea between 2008 and 2010 were used to examine the characteristics of natural mottled skate's spawning. The disc width and weight were measured up to $0.1 \mathrm{~cm}$ unit and $0.1 \mathrm{~g}$ unit. Samples were dissected to calculate the gonad mass up to the nearest $0.00 \mathrm{~g}$. The gonadosomatic index
(GSI) was calculated by the formula of (gonad weight / body weight) $\times 100$ and the hepatosomatic index (HSI) by the formula of (liver weight / body weight) $\times 100$. The gonads were dissected to examine the egg capsule development process in the ovaries and the number of fertilized eggs in each side of egg capsule right before spawning. We calculated the rate of egg capsule appearance and the number of fish with egg capsules, from the 706 sample females with the minimum disc width of $63 \mathrm{~cm}$ between February 2007 and March 2013, to investigate the peaked spawning season for the regulatory control of seasonal catch closure.

\section{Hatching conditions}

Forty egg capsules from six natural mottled skates [the disc width from 41.0 to $75.0 \mathrm{~cm}$ (average width of 65.1 $\mathrm{cm}$ ), body weight from 1.1 to $8.1 \mathrm{~kg}$ (average weight of $5.5 \mathrm{~kg}$ )] collected from trawl lines around Heuksan-do, Jeollanam Province and reared in the indoor tanks at Taean Breeding Research Center of the West Sea Fisheries Research Institute were examined. We investigated hatching temperatures at four different temperatures: $8^{\circ} \mathrm{C}$ (data collected from 19 December 2010 until 11 August 2011), $13^{\circ} \mathrm{C}$ (16 December 2010 to 30 June 2011), $18^{\circ} \mathrm{C}$ (26 December 2010 to 3 June 2011), and natural water temperature (30 April 2010 to 27 October 2010). The egg capsules were reared in $200 \mathrm{~L}$ fibre-reinforced plastic circular tanks with a minimum water depth of $40 \mathrm{~cm}$ The egg capsules were protected from floating matter using plastic baskets in the middle and the surface water layers in every rearing tank. Each tank had a $2 \mathrm{KW}$ heater to keep water temperature constant and a 2 mm thick transparent acrylic panel to minimize temperature change or evaporation. The water in the tanks was treated with water filter cartridges of 50 and 3 and supplied through a hose and exchanged water four to five times a day. The light intensity was controlled dark to keep it lower than 0 lux at all times except for 30 minutes for observation each day. The sea water salinity was maintained as in natural sea water (32 psu) and the dissolved oxygen 
was regulated with $7 \mathrm{mg} / \mathrm{L}$. A stocking density of ten egg capsules from each tank was examined for hatching time and rate.

\section{Hatching test in an artificial incubator}

The artificial incubator, invented by the West Sea Fisheries Research Institute at National Fisheries Research and Development Institute (patent number 10-1142038), is designed for multi-embryo egg capsules and made from fibrereinforced plastic with a size of $120 \mathrm{~cm}(\mathrm{~L}) \times 70 \mathrm{~cm}(\mathrm{~W})$ $\times 100 \mathrm{~cm}(\mathrm{H})$ and tank capacity of $350 \mathrm{~L}$. Each egg capsule taken from the egg container $[62.7 \mathrm{~cm}(\mathrm{~L}) \times 48 \mathrm{~cm}$ $(W) \times 6.8 \mathrm{~cm}(\mathrm{H})$ ] inside the incubator was managed in each container $[20 \mathrm{~cm}(\mathrm{~L}) \times 9 \mathrm{~cm}(\mathrm{~W}) \times 6.0 \mathrm{~cm}(\mathrm{H})]$. Eleven egg capsules (total length of $181.0 \pm 7.7 \mathrm{~mm}$ total weight of $125.7 \pm 25.4 \mathrm{~g}$ ) for hatching were collected from Daecheongdo, Incheon between 7 and 10 June 2012. They were delivered safely with oxygen vinyl packaging in a $10 \mathrm{~kg}$ styrofoam box. The incubator has a cooling system, a filtering system, and an oxygen supply system thus the water temperature is under control. Until the hatching moment, $120 \mathrm{~L}$ of water in the incubator was exchanged under a recirculating aquaculture system every ten days to avoid evaporation and salinity increasing. The water temperature was kept at $18.0 \pm 0.3^{\circ} \mathrm{C}$, salinity at $30.7 \pm 0.8$ psu, DO at $7.2 \pm 0.4 \mathrm{mg} / \mathrm{L}$, and the light intensity at natural light.

\section{RESULTS}

\section{Spawning characteristics}

The gonadosomatic index (GSI) from the sample females tends to increase as the body weight increases. The relation of gonad weight $(\mathrm{Gw})$ to the body weight $(\mathrm{Bw})$ was presented by $G w=51.203 B w-40.281\left(r^{2}=0.5244\right)$ (Fig. 1). The GSI from the sample females from 2008 to 2010 was 5.3 between January and March, 5.4 in April, and then started decreasing since spawning increases to 4.6 in May. The HSI of female mottled skate started decreasing from January and showed its lowest point in April at 4.1,
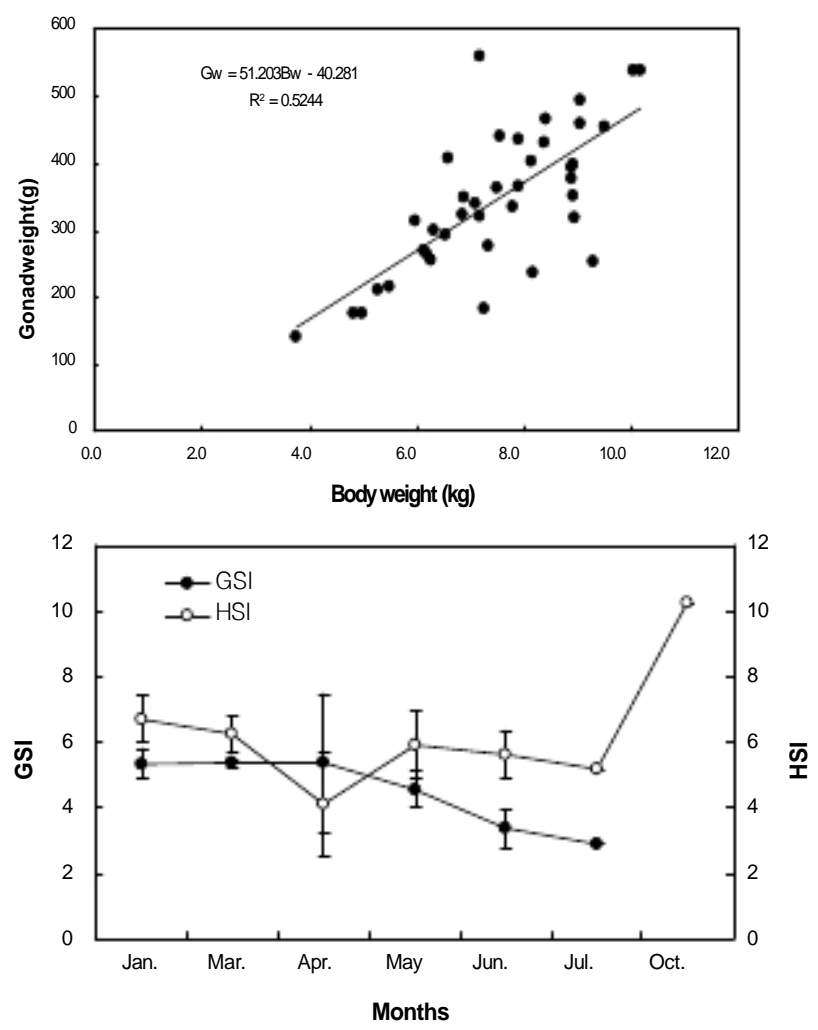

Fig. 1. Variations on gonad weight, according to body weight, the gonadosomatic index (GSI) and hepatosomatic index (HSI) of wild female Beringraja pulchra caught from 2008 to 2010.

which shows that GSI and HSI are inversely correlated (Fig. 1). As the mottled skate is oviparous, it produces eggs inside its egg capsules developing egg yolks. The capsules on both reproductive tracts in the ovaries are kelp leaf-shaped, rectangular, and fibrous with a thick layer. Each capsule can contain up to seven eggs (Figs. $3,4)$. The number of eggs in each egg capsule was as follows: one to seven (average 4) on the left reproductive tract and zero to six (average 4) on the right reproductive tract (Fig. 2). Forty females had 159 eggs on the left tract and 160 eggs on the right tract showing no significant difference (Fig. 2). Four eggs in the left egg capsule is the most common, occurring in 14 out of 40 cases (35\%) and four to five eggs in the right egg capsule is the most common, occurring in 13 out of 40 cases (32.5\%) (Table 1). The total number of eggs in both egg capsules in each sample was 3 to 13 (average of 8) showing significant 

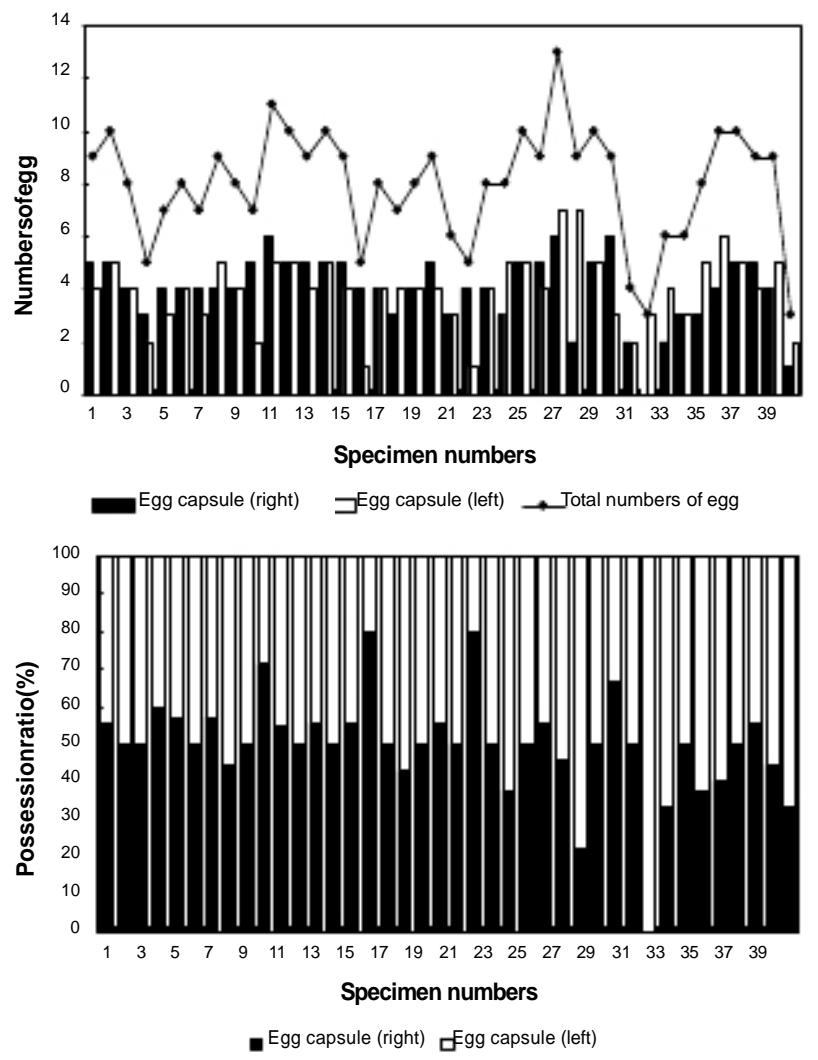

Fig. 2. Number of egg in the egg capsule and the possession ratio in both egg capsules of wild female Beringraja pulchra.

Table 1. Egg numbers within both egg capsule in the Beringraja pulchra ovaries

\begin{tabular}{cccccc}
\hline \multirow{2}{*}{$\begin{array}{c}\text { Egg numbers } \\
\text { within egg capsule }\end{array}$} & \multicolumn{2}{c}{ Egg capsule (left) } & & \multicolumn{2}{c}{ Egg capsule (right) } \\
\cline { 2 - 3 } \cline { 5 - 6 } & Number & Ratio (\%) & & Number & Ratio (\%) \\
\hline 0 & 0 & 0.0 & & 1 & 2.5 \\
1 & 2 & 5.0 & & 2.5 \\
2 & 4 & 10.0 & & 7.5 \\
3 & 6 & 15.0 & & 6 & 15.0 \\
4 & 14 & 35.0 & & 13 & 32.5 \\
5 & 11 & 27.5 & & 13 & 32.5 \\
6 & 1 & 2.5 & & 7.5 \\
7 & 2 & 5.0 & & 0 & 0.0 \\
\hline Total & 40 & 100.0 & 40 & 100.0 \\
\hline
\end{tabular}

difference (Fig. 2). The ratio of contained eggs in each side of an egg capsule represented no significant difference showing an average of $50.2 \%$ on the left side and average
Table 2. Investigation of main spawning period for the regulatory seasons of Beringraja pulchra from February 2007 to March 2013

\begin{tabular}{cccc}
\hline \hline Month of \\
collection & $\begin{array}{c}\text { Total number of } \\
\text { sample (*above } \\
\text { body length of } \\
\text { group sexual } \\
\text { maturity, A) }\end{array}$ & $\begin{array}{c}\text { Number } \\
\text { containing egg } \\
\text { capsules (B) }\end{array}$ & $\begin{array}{c}\text { Appear ratio of } \\
\text { egg capsule } \\
\text { (B/A, \%) }\end{array}$ \\
\hline 1 & 33 & 11 & 33.3 \\
2 & 42 & 7 & 16.7 \\
3 & 40 & 7 & 17.5 \\
4 & 95 & 25 & 26.3 \\
5 & 156 & 50 & 32.1 \\
6 & 83 & 22 & 26.5 \\
7 & 35 & 2 & 5.7 \\
8 & 35 & 1 & 2.9 \\
9 & 38 & 1 & 2.6 \\
10 & 51 & 1 & 2.0 \\
11 & 65 & 4 & 6.2 \\
12 & 33 & 2 & 6.1 \\
\hline Total & 706 & 133 & \\
$*$ Body length of group sexul maturity is & & \\
\hline
\end{tabular}

$49.8 \%$ on the right side. The results from examining 706 sample fish with a minimum disc width of $63 \mathrm{~cm}$ to regulate seasonal catch limits show that 133 females contained egg capsules in their ovaries. The percentage of egg capsules appearing in April was 26.3\%, May 32.1\%, and June 26.5\%. This indicates that spawning increased from April and peaked in May, which leads one to assume that the peak spawning of the mottle skate is from April to June (Table 2).

2. Hatching time and rate of egg capsule at various water temperature

Hatching at $8^{\circ} \mathrm{C}$ water temperature took 231 to 235 days (an average of 233) showing the slowest process and the longest hatching period. It took 196 to 201 days (an average of 199 ) at $13^{\circ} \mathrm{C}$, took 155 to 159 days (an average of 157 ) at $18^{\circ} \mathrm{C}$ and 180 to 185 days (an average of 183) at a natural water temperature from 12.8 to $24.2^{\circ} \mathrm{C}$ (an average of $19.5^{\circ} \mathrm{C}$ ). Although the average temperature 


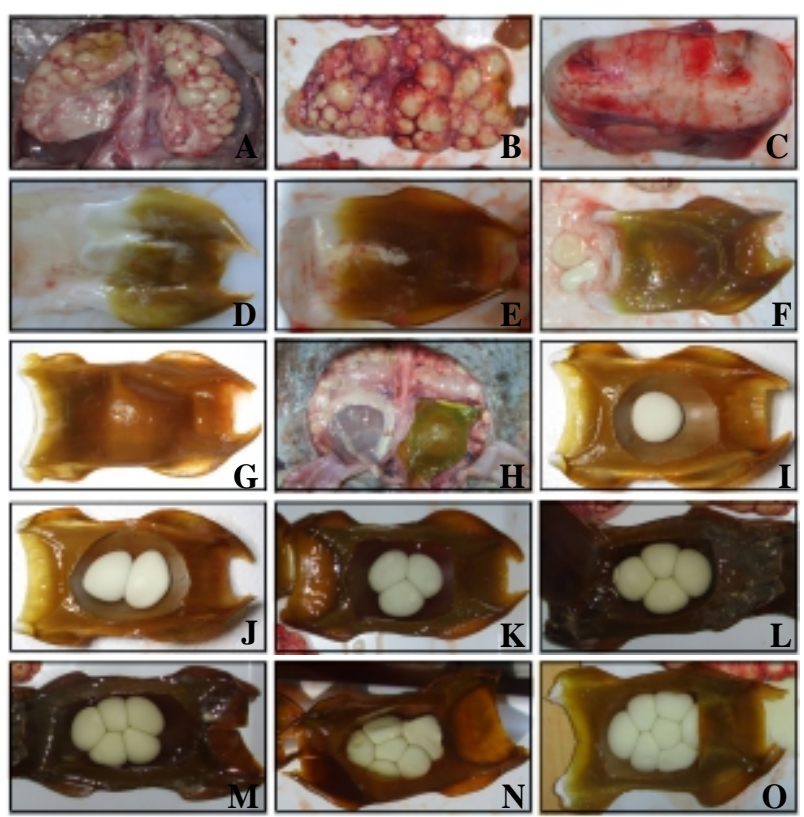

Fig. 3. Photographs of egg yolk and developing egg capsules in Beringraja pulchra. A: a number of egg yolk in the ovaries; $\mathrm{B}$ : right reproductive tract, $\mathrm{C}$ : developing egg yolk; D, E, F: developing egg capsule: G: completed egg capsule; $\mathrm{H}$ : both egg capsules contained in the ovaries; I: 1 fertilized egg in egg capsule; J: 2 fertilized eggs in the egg capsules; K: 3 fertilized eggs in egg capsule; L: 4 fertilized eggs in the egg capsule; M: 5 fertilized eggs in the egg capsules; $\mathrm{N}$ : 6 fertilized eggs in the egg capsules; O: 7 fertilized eggs in egg capsules.

for natural water was higher than $18^{\circ} \mathrm{C}$, the hatching was delayed and took longer since the natural water temperature at the early stage was low. The observation from the four different water temperature results in that the optimal hatching water temperature, considering hatching time, rate, and culture management is at $18^{\circ} \mathrm{C}$ (Table 3). Each experiment took five to six days from the fertilization until hatching.

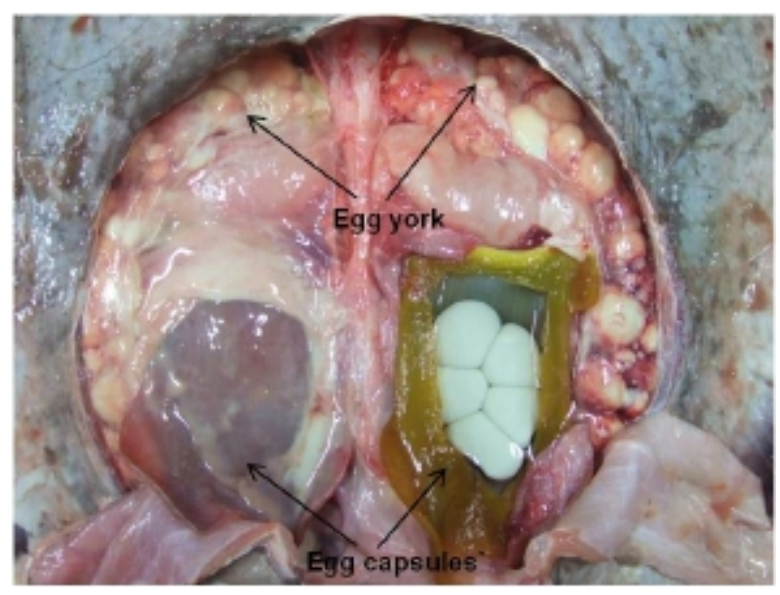

Fig. 4. Two egg capsules of female Beringraja pulchra.

3. Number of hatched larvae, hatching rate, sex ratio in the incubated egg capsule

From observing eleven egg capsules in the incubator (Fig. 7) at the maintained water temperature of $18^{\circ} \mathrm{C}$ for the hatching experiment, five out of eleven capsules showed normal formation before hatching. During the experiment, we supplied sea water repeatedly through a respiratory fissure to control weight change in an egg capsule, from which we observed more capsules where the weight increased after initially decreasing than from the capsules where the weight increased (Fig. 5). The number of newly hatched larvae that went through the normal hatching from the five egg capsules was 4 to 5 respectively and the hatching rate was $100 \%$. A portion of one side of the respiratory fissure on the anterior apron of the capsule opens and the eggs hatched out (Fig. 8). The hatched young mottled skates were $25 \%$ females and $75 \%$ males from the three capsules out of the five capsules and 60 to $80 \%$ females and 20 to $40 \%$ male from the

Table 3. The hatching time and hatching rate of Beringraja pulchra from the egg capsules incubated at different water temperatures

\begin{tabular}{lcccc}
\hline & \multicolumn{3}{c}{ Water temperature $\left({ }^{\circ} \mathrm{C}\right)$} \\
\cline { 2 - 5 } & 8 & 13 & 18 & *Natural condition \\
\hline Number of initial egg capsule & 14 & 16 & 18 & 10 \\
Number of hatched egg capsule & 11 & 14 & 16 & 10 \\
Hatching time (days) & $231 \sim 235$ & $196 \sim 201$ & $155 \sim 159$ & $180 \sim 185$ \\
Hatching rate (\%) & 78.6 & 87.5 & 88.9 & 100 \\
\hline
\end{tabular}

* Natural condition : $12.8 \sim 24.2^{\circ} \mathrm{C}$ (Mean $19.5^{\circ} \mathrm{C}$ ). 


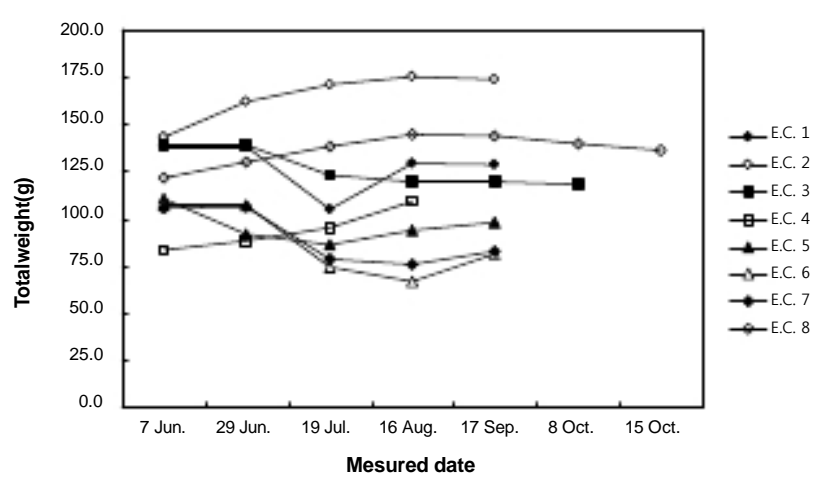

Fig. 5. Total weight variation of Beringraja pulchra egg capsules during incubation period, 2011.
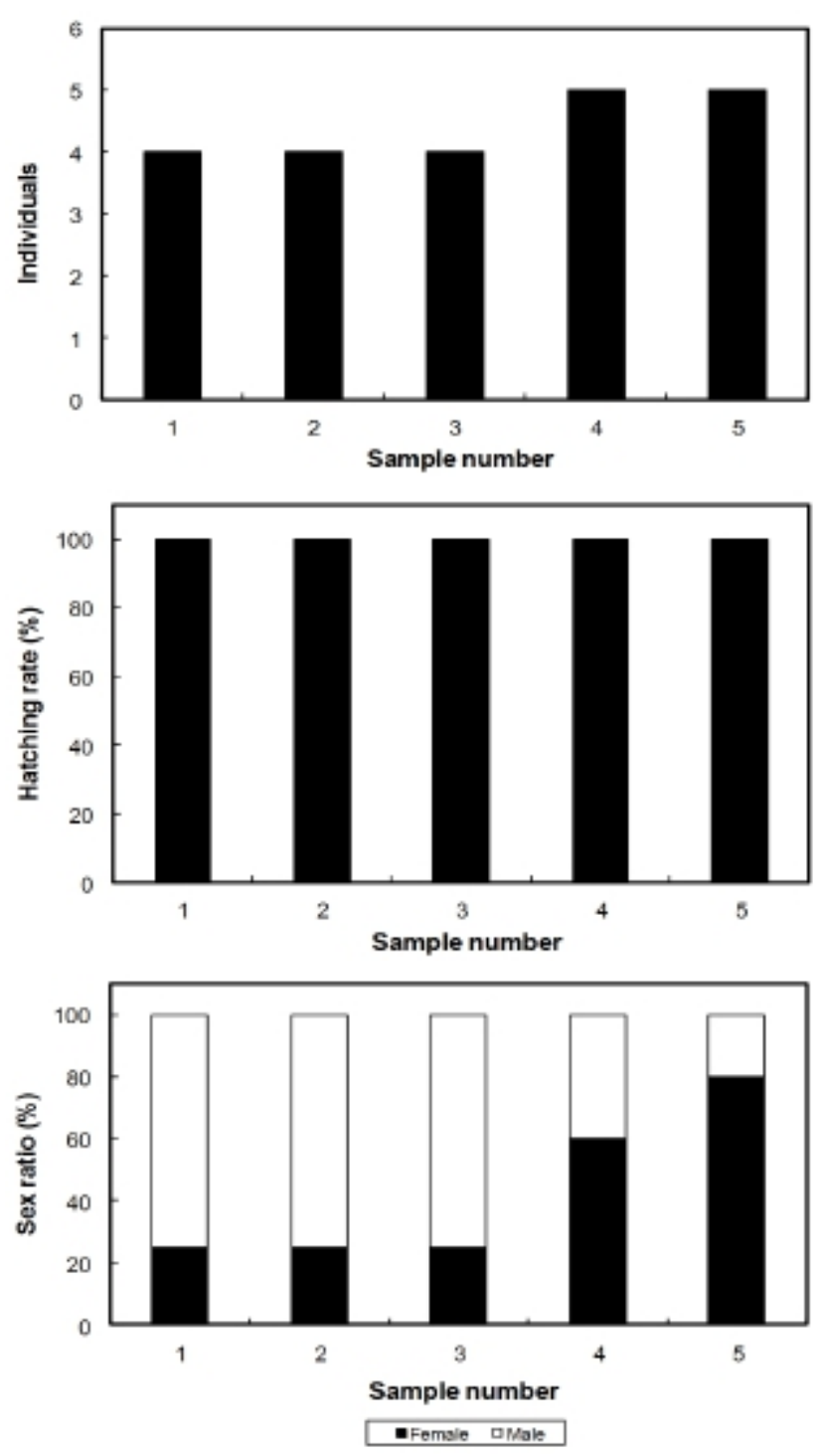

Fig. 6. Numbers of hatched larva, individual hatching rate and individual sex ratio of Beringraja pulchra using incubation device.

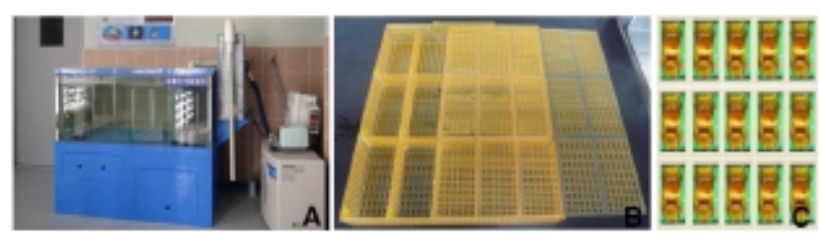

Fig. 7. Photographs of incubation device and egg capsule container of Beringraja pulchra. A: incubation device, B: egg capsule container, $\mathrm{C}$ : individual culture in egg capsule container.
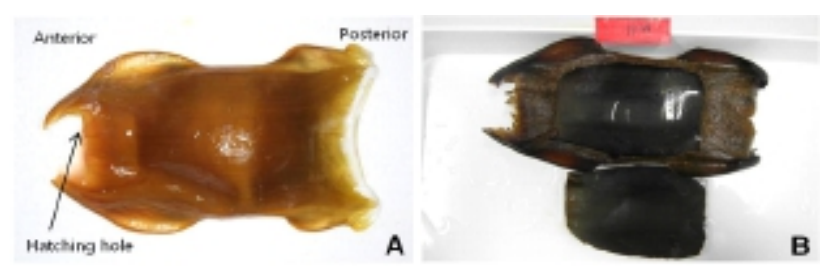

Fig. 8. Shape of egg capsule before and after hatching of Beringraja pulchra. A: hatching through pole of egg capsule anterior; B: inside of egg capsule after hatching.

other left two capsules. There were ten females (45.5\%) and twelve males (54.5\%) from the total of five egg capsules (Fig. 6).

\section{DISCUSSION}

The mottled skate is a native Korean species of big skate found along the coast of Heuksan-do and Daecheong-do, southwest of South Korea. It is one of the unique flavored food fish used in seafood stew and sashimi and commercially significant food fish. It inhabits shallow coastal waters of 30 to $200 \mathrm{~m}$ and it is cold water fish found in temperatures of 5 to $15^{\circ} \mathrm{C}$ (Jo et al., 2012). More research on its spawning and hatching should be conducted since its reproductive ecology has hardly studied. The mottled skate was originally classified as R. pulchra until it was renamed after Jeong's study (1999). As the relation of female gonad weight $(\mathrm{Gw})$ to the body weight $(\mathrm{Bw})$ was presented by $\mathrm{Gw}=51.203 \mathrm{Bw}-40.281\left(\mathrm{r}^{2}=0.5244\right)$, the gonad weight increase is followed by the increase in the body weight and body size rise corresponds to an egg number increase (Yeon et al., 1997). The GSI from the sample 
females was 5.4, peaking in April, and then decreased from May. When comparing to the previous data (Yeon et al., 1997; Jeong, 1999; Kim et al., 2005), it shows spawning peaks between April and June. However, the HSI was at its lowest point in April at 4.1, when the GSI was the highest. This indicates that the GSI and HSI are inversely correlated, like in other species such as damselfish (Chromis notatus) (Lee \& Lee, 1987; Lee \& Lee, 1988), yellowfin goby, Acanthogobius flavimanus (Park et al., 2005), and tongue sole, Cynoglossus semilaevis (Kang et al., 2012). The inverse correlation of HSI to GSI is inferred because during the oocyte development follicular cells secrete estradiol-17 $\beta$, which is conjugated in the liver. This contributes to RNA synthesis in the hepatocyte secreting vitellogenin, which makes up the protein content of the yolk in cytoplasm of the oocyte (Aida et al., 1973).

Comparing to other skates such as Okamejei kenojei (Jeong, 1999) and Hongeo koreana (Jeong \& Kim, 2009), the egg capsule of Beringraja pulchra is larger and has distinguishing keels, surface structure, and weight; weighing $125.7 \pm 25.4 \mathrm{~g}$ on average. Most of the egg capsules in the skates like H. koreana (Jeong \& Kim, 2009) and Raja North Pacific (Ishihara, 1987; Ishihara et al., 2005) are covered by thin fibers. However, egg capsules' surface of the skate is rather rough and thick. Females laid a pair of egg capsules on both tracts developing egg yolks in the ovary. The previous reports showed that each egg capsule can contain up to nine eggs (Jo et al., 2010). In the present research, however, a maximum of seven eggs per egg capsule were observed. From examining forty mottled skates, the total number of eggs in both egg capsules was 159 on the left tract and 160 on the right tract representing no statistical difference, showing balanced reproductive tracts (Jo et al., 2010). From the survey of female mottled skates with a disc width of $63 \mathrm{~cm}$ for a year, we found the rate of appearing egg capsules peaked in May, which led us to believe the main spawning period is from April to June (26.3 to 32.1\%). This result corresponded to the indirectly estimated GSI during the spawning period and to previous research (Yeon et al.,
1997). Also, the mottled skate was shown to employ internal fertilization by mating since it deposits eggs after fertilization occurs. It shows that the follicle diameter increases after developing egg yolks in the ovaries (Yeon et al., 1997). A classification of the spawning behaviours of elasmobranches, like sharks and skates, are patterned on the spawning period; all year spawners, once or twice a year spawning, or spawns in a year or two year intervals. The Korean female skates are classified into the second pattern based on the period when the majority of its egg capsules appear (Yeon et al., 1997; Kim et al., 2005).

For the research, the incubated egg capsules were collected from the skate fish that were stored in tanks and aquariums since it is hard to get fertilized eggs from wild skates, and it is not known where they lay egg capsules (Luer \& Gilbert, 1985; Luer et al., 2007). Studies on its life cycle and embryotic development have rarely been done, since it is difficult to observe the forming process from its thick and non transparent egg capsules. A few related studies have been done; a functional analysis of the embryotic development period (Pardue et al., 1995), a respiratory analysis of external gills (Pelster \& Bemis, 1992), and caudal fin's function (Leonard et al., 1999). The egg capsules from the mottled skate (Beringraja pulchra) and clearnose skate (Raja eglanteria) show well developed respiratory fissures, so they supply embryos fresh water circulating freely from outside of the capsule and helps embryos breathe (Luer et al., 2007; Jo et al., 2010). The present research also observed a weight change according to fresh water circulation during the embryotic development in the capsules and some eggs became buoyant.

Hatching time of the skates varied depending on the water temperature. As for the Alaska skate, Bathyraja parmifera, it took the longest, 1,290 days at $4.4^{\circ} \mathrm{C}$. In case of $O$. kenojei, it is known to take 137 days at $14.6^{\circ} \mathrm{C}$ (Hoff, 2008). This study showed that the mottled skate takes an average of 233 days at $8^{\circ} \mathrm{C}$, an average of 199 days at $13^{\circ} \mathrm{C}$, and an average of 157 days at $18^{\circ} \mathrm{C}$. The results demonstrate that hatching occurs faster when the water temperature increases. The survival rate was $88.9 \%$ 
H-W Kang, Y-R Jo, D-Y Kang, G-S Jeong, H-S Jo

at $18^{\circ} \mathrm{C}$, which concludes that the optimal water temperature for artificial hatching is $18^{\circ} \mathrm{C}$. The mottled skate is known as a cold water species (Jo et al., 2012), but its hatching is optimal at $18^{\circ} \mathrm{C}$. Clearnose skate, Raja eglanteria hatched in 85 days at $20^{\circ} \mathrm{C}$, showing that higher water temperature shortens the hatching time. The embryotic survival was dependant on the water temperature variation showing that embryos did not develop where the water temperature was either below $12^{\circ} \mathrm{C}$ or above $25^{\circ} \mathrm{C}$ (Luer et al., 2007).

From the five egg capsules in the incubator, 22 larvae were artificially hatched with the sex ratio was $45.5 \%$ female and $54.5 \%$ male. Further studies on the sex ratio of hatched larvae, depending on the water temperature, are needed. In addition, techniques for artificial hatching for female mottled skate production should be developed since females grow faster and taste better. Artificially hatched eggs of oblong rockfish, Sebastes oblongus at $18^{\circ} \mathrm{C}$ were all females from the experiment (Kwak et al., 2006). Genetical factors and environmental factors determine physiological sex of vertebrate animals like reptiles and vertebrate fish (Pieau et al., 1994), and the water temperature is known to be one of the most influential factors (Lang \& Andrews, 1994; Baras et al., 2001; King et al., 2013).

Since the results from this paper identified the egg capsule formation, the number of larvae in the egg capsule, main spawning period, hatching time at the various water temperature, and hatching rate, this study will provide fundamental data and information for artificial reproduction of the mottled skate.

\section{ACK NOWLEDGEMENTS}

This work was supported by grants from the National Fisheries Research and Development Institute (NFRDI) in Korea (RP-2013-AQ-175).

\section{REFERENCES}

Aida K, Nagahama Y, Hibiya T (1973) Physiological studies on the gonadal maturation of fish. I. Sexual difference on composition of plasma protein of ayu in relation to gonadal maturation. Bull Jap Soc Sci Fish 39:10911106.

Baras E, Jacobs B, Me'lard C (2001) Effect of water temperature on survival, growth and phenotypic sex of mixed $(\mathrm{XX}-\mathrm{XY})$ progenies of Nile tilapia Oreochromis niloticus. Aquacul 192:187-199.

Hoff GR (2008) A nursery site of the Alaska skate (Bathyraja parmifera) in the eastern Bering Sea. Fish Bull 106:233-244.

Hong SH, Yeon IJ, Im YJ, Hwang HJ, Ko TS, Park YC (2000) Feeding habits of Okamejei kenojei in the Yellow Sea. Bull Nat'l Fish Res Dev 58:1-9.

Ishihara H (1987) Revision of the Western North Pacific species of the genus Raja. J Ichthol 34:241-285.

Ishihara H, Homma K, Jeong CH (2005) Comparative morphological study of the egg capsules of skates (Pisces: Rajiformes). J Japan Drift Soc 3:31-41.

Ishihara $\mathrm{H}$, Treloar $\mathrm{M}$, Bor PHF, Senou $\mathrm{H}$, Jeong $\mathrm{CH}$ (2012) The comparative morphology of skate egg capsules (Chondrichthyes: Elasmobranchii: Rajiformes). Bul. Kanagawa prefect. Mus (Nat Sci) 41:9-25.

Jeong CH (1999) A review of taxonomic studies and common names of Rajid fishes (Elasmobranchii, Rajidae) from Korea. Kor J Ichthyol 11:198-210.

Jeong CH (2000) Fauna and geographical distribution of batoid fishes (Pisces, Chondrichthyes) from Korea. J Korean Soc Fish Res 3:97-106.

Jeong CH, Kim JK (2009) Egg capsule of Hongeo koreana (Chondrichthyes: Rajiformes: Rajiidae). Korean J Ichthyol 21:283-286.

Jo HS, Kang EJ, Chp YR, Seo HC, Im YJ, Hwang HJ (2010) Characteristics of multi-embryo egg capsule and larvae of Mottled Skate Raja pulchra from Korea. Korean J Ichthyol 22:217-224.

Jo HS, Hwang HJ, Kwon DH, Jeong GS, Choi KH, Cha BR, Im YJ (2011) Fishing characters of Skate ray, Raja pulchra by the offshore longline fishery in Heuksan- 
do, Korea. J Kor Soc Fish Tech 47:403-410.

Jo HS, Kim KH, Kim MJ, Kim HJ, Im YJ, Kwon DH, Heu MS, Kim JS (2012) Sensory characterization of domestic Mottled Skate Beringraja pulchra as affected by area caught, sex, and weight. Kor J Fish Aquat Sci 45:619-626.

Jo HS, Kim KH, Kim MJ, Kim HJ, Kwon DH, Im YJ, Heu MS, Kim JS (2013) A comparison of the taste and nutritional properties of domestic Mottled Skate Beringraja pulchra according to the area caught, sex, and weight. Kor J Fish Aquat Sci 46:129-138.

Kang HW, Lim HK, Kang DY, Han HS, Do YH, Park JS (2012) Maturation and spawning of the female tongue sole, Cynoglossus semilaevis in the West Coast of Korea. Dev Reprod 16:87-93.

Kang JH, Park JY, Jo HS (2012) Rapid development of microsatellite markers with 454 pyrosequencing in a vulnerable fish, the mottled skate, Raja pulchra. Int J Mol Sci 13:7199-7211.

Kim IS, Choi Y, Lee CL, Lee YJ, Kim BJ, Kim JH (2005) Illustrated Book of Korean Fishes. Kyo-Hak Publishing Co., Ltd. 615pp.

Kim JK, Sim DS, Jeong SD (2005) Sexual maturity of Raja koreana (Elasmobranchii, Rajoidei) from Korea. Korean J Ichthyol 17:229-235.

King R, Cheng WH, Tseng CT, Chen HC, Cheng IJ (2013) Estimating the sex ratio of green sea turtles (Chelonia mydas) in Taiwan by the nest temperature and histological methods. J Exp Mar Bio Ecol 445: 140-147.

Kwak EJ, Lee KW, Choi NH, Park CK, Han KH, Lee WK (2006) Gonadal development and sex ratio of artificial seedlings of the Oblong rockfish Sebastes oblongus. J Kor Fish Soc 39:297-302.

Lang JW, Andrews HW (1994) Temperature dependent sex differentiation in crocodilians. J Exp Zool 270:28-44. Lee YD, Lee TY (1987) Studies on the reproductive cycle of damselfish, Chromis notatus (Temminck et Schlegel). J Kor Fish Soc 20:509-519.

Lee YD, Lee TY (1988) Change in activity of liver cells and GTH cells according to sexual maturation of Chromis notatus. Annal reports Jeju Uni 12:73-78.

Leonard JB, Summers KAP, Koob TJ (1999) Metabolic rate of embryonic little skate, Raja erinacea (Chondrichthyes: Batoidea): The cost of active pumping. J Exp Zool 283:13-18.

Luer CA, Gilbert PW (1985) Mating behavior, egg deposition, incubation period, and hatching in the clearnose skate, Raja eleganteria. Env Biol Fishes 13:161-171.

Luer CA, Walsh CJ, Bodine AB, Wyffels JT (2007) Normal embryonic development in the clearnose skate, Raja eglanteria, with experimental observations on artificial insemination. Environ Biol Fish 80:239-255. Pardue MT, Luer CA, CallenderMG, Chou BR, Sivak JG (1995) The absence of a photopic influence on the refractive development of the embryonic eye of the clearnose skate (Raja eleganteria). Vision Res 25:16751678.

Park MH, Hwang IJ, Kim DJ, Lee YD, Kim HB, Baek HJ (2005) Gonadal development and sex steroid hormone levels of the yellowfish goby Acanthogobius flavimanus. J Kor Fish Soc 38:309-315.

Pelster B, Bemis WE (1992) Structure and function of the external gill filaments of embryonic skates (Raja erinacea). Res Physiol 89:1-13.

Pieau C, Girondot M, Richard-Mercier N, Desvages G, Dorizzi M, Zaborski P (1994) Temperature sensitivity of sex differentiation of gonads in the European pond turtle; hormonal involvement. J Exp Zoo 270:86-94.

Wourms JP (1977) Reproduction and development in chondrichthyan fishes. Am Zool 21:473-515.

Yeon IJ, Hong SH, Park YC, Kim ST, Cha HK (1997) The reproduction of Raja pulchra Liu in the Yellow Sea. Bull Natl Fish Res Dev Inst 53:23-26. 